\title{
Milk yield and milking station visits of primiparous versus multiparous cows on automatic milking system farms in the Upper Midwest United States
}

\author{
J. M. Siewert, ${ }^{1}$ J. A. Salfer, ${ }^{2}$ and M. I. Endres ${ }^{1 *}$ \\ ${ }^{1}$ Department of Animal Science, University of Minnesota, St. Paul 55108 \\ ${ }^{2}$ St. Cloud Regional Extension Center, University of Minnesota, St. Cloud 56301
}

\begin{abstract}
The objective of this study was to investigate milk yield and frequency of visits to the milking station of primiparous versus multiparous cows at different stages of lactation on farms with automatic milking systems (AMS) in the Upper Midwest United States. Forty farms were included in the study, and daily AMS software data were collected for 18 mo. For the investigation of milk yield and milking visits, stage of lactation was categorized into 14 periods, $7 \mathrm{~d}$ in length for the first $28 \mathrm{~d}$ in milk (DIM) and $30 \mathrm{~d}$ in length thereafter until 328 DIM. Cow traffic flow to the AMS (free or guided) was included in the model. For the evaluation of failures and refusals, stage of lactation was categorized into 6 periods, $7 \mathrm{~d}$ in length each for the first 28 DIM, and 2 periods of $150 \mathrm{~d}$ in length each thereafter until 328 DIM. Failures are milking station visits where a cow fails to be milked due to lack of machine attachment although it is time for the cow to be milked. Refusals are milking station visits before adequate time has passed since previous milking, thus the cow leaves the milking station without being milked. Data from lactation days beyond 328 DIM were excluded from the study. Primiparous cows in free-flow systems produced less milk than multiparous cows until the 11th stage of lactation and produced more milk from the 12th stage until the end of the study period. Primiparous cows in guided-flow systems produced less milk than multiparous cows all 14 stages of lactation, but were approaching the milk yield of multiparous cows at the end of the study period. This was a biologically normal lactation curve for primiparous cows. However, estimated peak ratio (primiparous vs. multiparous cows'
\end{abstract}

Received July 13, 2018.

Accepted December 1, 2018.

*Corresponding author: miendres@umn.edu peak milk yield) was lower than industry standards. Both traffic flow systems had fewer milking visits for primiparous cows compared with multiparous cows in early lactation. This lower milking frequency persisted until the 11th stage of lactation in free-flow systems. In guided-flow systems, primiparous cows were milked less frequently until the 5th stage of lactation, had similar milking frequency in the 6th stage of lactation, and were milked more frequently thereafter. Failures were greater for primiparous cows during all stages of lactation. However, the greatest differences were detected in the early stages of lactation. Primiparous cows had 0.067 more failures/cow per day on average than multiparous cows during wk 1 of lactation. For the remaining lactation stages, differences in failures ranged from 0.003 to 0.039 . Refusals were less frequent (0.4 to $0.6 / \mathrm{d}$ ) for primiparous cows during the first 2 wk of lactation, similar for wk 3 of lactation, and more frequent for the remaining lactation stages $(0.10$ to $0.14 / d)$. Failures and refusals were only evaluated in free-flow systems. These findings appear to indicate a potential lagging performance for primiparous cows in early lactation as compared with multiparous cows. Additional investigation into improving the adaptation of primiparous cows to AMS in early lactation may be warranted.

Key words: automatic milking system, milk yield, milking frequency, parity

\section{INTRODUCTION}

To improve the efficiency of automatic milking systems (AMS) it is critical to understand how cows interact with AMS. Based on previous discussions with AMS farmers and consultants, it seemed to us that evaluating aspects of AMS efficiency for primiparous cows as compared with multiparous cows was warranted. Factors of interest in the evaluation of AMS efficiency include daily milk yield per cow and frequency of visits to the AMS including successful milkings, failures, and refusals. Fetching is also a factor that can affect ef- 
ficiency of AMS along with milking permission settings. Although most cows visit the AMS voluntarily, farm workers need to routinely bring cows to the AMS when they fail to visit the AMS milking station on time as defined by the permission settings for milking interval on each farm. These cows are flagged by the AMS software in a daily attention list and need to be fetched.

Early research aiming to understand how cows interact with the AMS found that providing concentrate feed as an incentive to entice cows to the AMS station was necessary to achieve acceptable milking frequency rates (Ketelaar-de Lauwere et al., 1999). The opportunity to obtain palatable feed has been shown to be a greater motivator for cows to visit the milking station than the opportunity to be milked, thus relieving pressure on the udder (Prescott et al., 1998). Cows that failed to be milked, due to either equipment failure or cow-related factors, produced less milk in the following milking event, on a milk yield per hour adjusted basis (Bach and Busto, 2005), and returned to be milked sooner, reducing the AMS efficiency (Stefanowska et al., 1999). Refusals result from cows visiting the AMS before sufficient time has passed since their previous milking visit according to permission settings. These refusals may hinder AMS efficiency, as the milking station is being occupied by a cow that is not ready to be milked rather than being available for cows that are due for milking. However, a high number of refusals may also indicate a good cow flow to the AMS milking station and it should not cause problems as long as there is enough free time on the AMS.

Tremblay et al. (2016) found free-flow cow traffic to be associated with greater milk yield per cow compared with guided-flow traffic. In free-flow cow traffic farms, cows can freely move among the feeding, resting, and AMS station areas without guidance by one-way gates to the AMS station or a sorting system that determines if the cow must first be milked before being released to the feeding or resting area. The latter is what happens in a guided-flow system.

The objective of this study was to compare daily milk yield and visits (milking, failures, or refusals) to the AMS of primiparous versus multiparous cows at different stages of lactation and with either free- or guidedflow cow traffic. Our hypothesis was that primiparous cows would not be as productive or use the AMS as efficiently as multiparous cows and their response would be influenced by type of cow traffic flow. The study results would suggest a need to further investigate AMS management practices and facility design recommendations that could improve AMS efficiency and cow performance in AMS.

\section{MATERIALS AND METHODS}

\section{Farms and Data Collection}

Forty farms using AMS in the Upper Midwest United States (Minnesota and Wisconsin) were enrolled in the current study. This sample size represented approximately $80 \%$ of AMS farms (based on AMS dealer information) in the region at the time of the study that met the study requirement of a minimum of $2 \mathrm{yr}$ using AMS. In addition, these were farms without technical issues preventing downloading of daily software data needed for analysis. Thirty-nine farms had Holsteins and 1 farm had Jerseys. Farms used Lely Astronaut (Lely Industries NV, Maassluis, the Netherlands) or DeLaval VMS (DeLaval International AB, Tumba, Sweden) AMS to milk their cows. Thirty-one of the farms used a free-flow cow traffic system (30 Lely and 1 DeLaval) and 9 used guided-flow cow traffic (all DeLaval). All farms in the current study housed their lactating cows in barns with no access to pasture. Approximately 18 mo of daily data (mid-2013 to the end of 2014) for individual cows automatically recorded by each farm's AMS software were collected, including milk yield and visits to the AMS station, as well as data on lactation number (parity) and DIM.

Data collected from the software were used to evaluate the association of parity, stage of lactation, and cow traffic flow system (free flow or guided flow) with milking visits and milk yield per cow per day. In freeflow traffic systems, cows have unrestricted access to the feeding area, lying area, and AMS unit at all times. In guided-flow traffic systems, cows must visit areas of the barn in sequence, such as from lying area to the AMS unit to the feeding area, using a combination of pre-selection and one-way gates. Stage of lactation was categorized into 14 periods: 4 stages, each $7 \mathrm{~d}$ in length for the first 28 DIM after calving (stages 1 to 4 ), a time of rapidly changing milking frequency and acclimation to the AMS, and 10 additional stages, each $30 \mathrm{~d}$ in length, from 29 to 328 DIM (stages 5 to 13 ).

We also collected data on failures and refusals from a subset of 30 free-flow cow traffic farms using Lely AMS as we had technical difficulties obtaining these data for the DeLaval farms. Failures are milking station visits where a cow fails to be milked due to lack of machine attachment although it is time for the cow to be milked based on milking permission settings. Refusals are milking station visits before adequate time has passed since previous milking, thus the cow leaves the milking station without being milked. Stage of lactation for the analysis of failures and refusals was categorized into 6 
periods: $7 \mathrm{~d}$ in length each for the first 28 DIM (stages 1 to 4 ), and $150 \mathrm{~d}$ in length each thereafter until 328 DIM (stages 5 and 6). Data from lactation days beyond 328 DIM were excluded from the study.

\section{Statistical Analysis}

Milk Yield and Milking Visits. Data were analyzed using linear mixed models. The normality of milk yield and milking visits data was assessed by univariable analysis (PROC UNIVARIATE, SAS 9.4, SAS Institute Inc., Cary, NC). Histograms of the data were used to evaluate normality. Model assumptions were evaluated using a scatter plot of the residuals and quantile-quantile plots. The model was fit using Proc MIXED (SAS 9.4) with the LSMEANS and PDIFF option used to investigate differences in milk yield $(\mathrm{kg} / \mathrm{d})$ and AMS milking visits (milkings/d), the 2 outcome variables of interest in the current study, by parity and traffic flow system within stages of lactation. Fixed effects included cow traffic flow (free or guided), parity ( 1 or $\geq 2$ ), stage of lactation (as described previously), as well as all possible 2-way and 3-way interactions. Brand of AMS was not included in the model as there was only 1 farm within the free-flow farm data set of a different brand than the other farms on that data set. Removal of this farm from the data set did not influence results and the farm was included in the final analysis. In addition, the Jersey herd was not excluded from the milk yield analysis because doing so had no significant effect on the interpretation of the results. Farm was used as a random effect. Associations were considered significant at $P \leq 0.05$ and tendencies at $P$ $>0.05$ to $<0.10$. The assumptions of the models were evaluated using residual plots.

Failures and Refusals. The distribution of visit frequency data was assessed by univariable analysis (PROC UNIVARIATE, SAS 9.4). Failures and refusals per day were evaluated using the NLMIXED procedure (SAS 9.4, SAS Institute Inc.). This procedure was used to fit the mixed effect zero-inflated Poisson regression. The NLMIXED procedure requires input of starting values for the parameter estimates in the Parms statement. These starting values for the fixed effect parameters of stage of lactation, parity, and stage of lactation by parity interaction were obtained using a zero-inflated poison regression with GENMOD procedure (SAS 9.4). The GLIMMIX procedure (SAS 9.4) was used to obtain the starting value for the random effect of cow ID. These starting values were used on the Parms statement of the NLMIXED procedure. Associations were considered significant at $P \leq 0.05$ and tendencies at $P>0.05$ to $<0.10$.

\section{RESULTS AND DISCUSSION}

\section{Analysis of Milk Yield and Milking Visits}

We collected 2,858,514 daily cow records for milk yield from the 40 farms enrolled in the current study. We found that all main effects, and 2-way and 3-way interactions were associated $(P<0.001)$ with milk yield. In free-flow systems, primiparous cows produced less milk than multiparous cows from the beginning of lactation until the 11th stage of lactation (238 DIM) and produced more milk from the 12th stage until the end of the study period (239 to 328 DIM). In contrast, primiparous cows produced less milk than multiparous cows all 14 stages of lactation in guided-flow systems. This result indicates a biologically normal lactation curve for primiparous cows as they normally peak later in lactation, produce less milk, and are more persistent than multiparous cows. However, estimated peak ratio (primiparous vs. multiparous cows' peak milk yield) was lower than industry standards at $74 \%$ for free-flow and $71 \%$ for guided-flow systems. The recommended standard for peak milk of primiparous cows would be $75 \%$ of peak milk production for third lactation and greater cows and $80 \%$ for second lactation cows (https: //pubs.ext.vt.edu/404/404-285/404-285.html).

We found differences and trends within parity and between traffic flow systems during some of the early stages of lactation (Table 1). In all instances where a difference or trend was detected, cows in free-flow systems produced more milk $(P<0.05)$ than those in guided-flow systems. However, results from the current study should be taken with caution because the number of guided-flow farms was relatively small $(\mathrm{n}=9)$. In addition, design and management of guided-flow systems might have improved since the current study was conducted. Tremblay et al. (2016) also reported that farms with free-flow systems had greater milk yield than those with guided-flow systems. Rodenburg (2017) in a review of the literature suggested that free flow should be the preferred management option as studies indicated that free flow was associated with higher milk yield, more meals, higher feed intake, and longer resting times. However, guided flow was associated with less fetching, reducing labor.

We collected 2,858,514 daily cow records for milking frequency (daily visits to the AMS milking station with successful milkings) from the 40 farms enrolled in the current study. In both free- and guided-flow systems, primiparous cows visited the AMS less frequently $(P<$ 0.05 ) than multiparous cows in early lactation (Table 2). Primiparous cows had lower milking frequency than multiparous cows the first 9 lactation stages (until 178 
Table 1. Estimated milk yield (kg/d) by cow traffic flow system (free or guided) and parity (primiparous = lactation 1 ; multiparous = lactation $\geq 2$ ) at different stages of lactation (DIM) on 40 farms with automatic milking systems in Minnesota and Wisconsin

\begin{tabular}{|c|c|c|c|c|c|}
\hline \multicolumn{2}{|c|}{ Stage of lactation } & \multicolumn{2}{|c|}{ Free-flow traffic system ${ }^{1}$} & \multicolumn{2}{|c|}{ Guided-flow traffic system ${ }^{2}$} \\
\hline Stage & DIM & Primiparous & Multiparous & Primiparous & Multiparous \\
\hline 1 & $1-7$ & $16.2^{\mathrm{a}}$ & $24.2^{\mathrm{b}}$ & $12.8^{\mathrm{a}}$ & $23.9^{\mathrm{b}}$ \\
\hline 2 & $8-14$ & $23.7^{\mathrm{a}, \mathrm{c}}$ & $35.5^{\mathrm{b}}$ & $18.1^{\mathrm{a}, \mathrm{d}}$ & $32.9^{\mathrm{b}}$ \\
\hline 3 & $15-21$ & $26.9^{\mathrm{a}, \mathrm{c}}$ & $39.5^{\mathrm{b}}$ & $20.5^{\mathrm{a}, \mathrm{d}}$ & $36.3^{\mathrm{b}}$ \\
\hline 4 & $22-28$ & $28.9^{\mathrm{a}, \mathrm{c}}$ & $41.9^{\mathrm{b}, \mathrm{e}}$ & $22.4^{\mathrm{a}, \mathrm{d}}$ & $38.2^{\mathrm{b}, \mathrm{f}}$ \\
\hline 5 & $29-58$ & $31.0^{\mathrm{a}, \mathrm{c}}$ & $43.6^{\mathrm{b}}$ & $25.0^{\mathrm{a}, \mathrm{d}}$ & $40.2^{\mathrm{b}}$ \\
\hline 6 & $59-88$ & $32.1^{\mathrm{a}, \mathrm{c}}$ & $42.7^{\mathrm{b}}$ & $27.1^{\mathrm{a}, \mathrm{d}}$ & $40.0^{\mathrm{b}}$ \\
\hline 7 & $89-118$ & $32.2^{\mathrm{a}, \mathrm{e}}$ & $40.6^{\mathrm{b}}$ & $28.5^{\mathrm{a}, \mathrm{f}}$ & $38.6^{\mathrm{b}}$ \\
\hline 8 & $119-148$ & $31.8^{\mathrm{a}}$ & $38.4^{\mathrm{b}}$ & $28.6^{\mathrm{a}}$ & $36.9^{\mathrm{b}}$ \\
\hline 9 & $149-178$ & $31.2^{\mathrm{a}}$ & $36.1^{\mathrm{b}}$ & $28.1^{\mathrm{a}}$ & $34.9^{\mathrm{b}}$ \\
\hline 10 & $179-208$ & $30.5^{\mathrm{a}}$ & $33.8^{\mathrm{b}}$ & $27.4^{\mathrm{a}}$ & $32.6^{\mathrm{b}}$ \\
\hline 11 & $209-238$ & $29.6^{\mathrm{a}}$ & $31.2^{\mathrm{b}}$ & $27.0^{\mathrm{a}}$ & $30.2^{\mathrm{b}}$ \\
\hline 12 & $239-268$ & $28.3^{\mathrm{a}}$ & $28.1^{\mathrm{b}}$ & $26.2^{\mathrm{a}}$ & $27.8^{\mathrm{b}}$ \\
\hline 13 & $269-298$ & $26.4^{\mathrm{a}}$ & $25.0^{\mathrm{b}}$ & $24.8^{\mathrm{a}}$ & $25.4^{\mathrm{b}}$ \\
\hline 14 & $299-328$ & $25.4^{\mathrm{a}}$ & $23.0^{\mathrm{b}}$ & $23.6^{\mathrm{a}}$ & $23.7^{\mathrm{b}}$ \\
\hline
\end{tabular}

${ }^{\mathrm{a}, \mathrm{b}}$ Parity within traffic flow system and stage of lactation differ $(P<0.05)$.

${ }^{\mathrm{c}, \mathrm{d}}$ Traffic flow system within parity and stage of lactation differ $(P<0.05)$.

${ }_{\mathrm{e}, \mathrm{f}}^{\mathrm{f}}$ Traffic flow system within parity and stage of lactation tend to differ $(P<0.10)$.

${ }^{1}$ Pooled SE $=1.01$.

${ }^{2}$ Pooled $\mathrm{SE}=1.87$.

DIM), had similar milking frequency during the 10th lactation stage (178-208 DIM), and had greater milking frequency for the remainder of the lactation than multiparous cows in free-flow systems. Cows in guidedflow systems followed a slightly different pattern than those in free-flow systems. Primiparous cows had lower milking frequency through the first 5 stages of lactation (until 58 DIM), had greater milking frequency or tended to have greater milking frequency from 6th to 10th lactation stage, and had similar milking frequency to multiparous for the remainder of the lactation. It would also be worth considering variability in the milk-

Table 2. Estimated successful milking visits per day by cow traffic flow system (free or guided) and parity (primiparous $=$ lactation 1 ; multiparous $=$ lactation $\geq 2$ ) at different stages of lactation (DIM) on 40 farms with automatic milking systems in Minnesota and Wisconsin

\begin{tabular}{|c|c|c|c|c|c|}
\hline \multicolumn{2}{|c|}{ Stage of lactation } & \multicolumn{2}{|c|}{ Free-flow traffic system ${ }^{1}$} & \multicolumn{2}{|c|}{ Guided-flow traffic system ${ }^{2}$} \\
\hline Stage & DIM & Primiparous & Multiparous & Primiparous & Multiparous \\
\hline 1 & $1-7$ & $2.03^{\mathrm{a}}$ & $2.61^{\mathrm{b}}$ & $1.94^{\mathrm{a}}$ & $2.52^{\mathrm{b}}$ \\
\hline 2 & $8-14$ & $2.26^{\mathrm{a}}$ & $3.14^{\mathrm{b}, \mathrm{e}}$ & $2.15^{\mathrm{a}}$ & $2.69^{\mathrm{b}, \mathrm{f}}$ \\
\hline 3 & $15-21$ & $2.47^{\mathrm{a}, \mathrm{g}}$ & $3.18^{\mathrm{b}, \mathrm{e}}$ & $2.31^{\mathrm{a}, \mathrm{h}}$ & $2.73^{\mathrm{b}, \mathrm{f}}$ \\
\hline 4 & $22-28$ & $2.60^{\mathrm{a}}$ & $3.15^{\mathrm{b}, \mathrm{e}}$ & $2.49^{\mathrm{a}}$ & $2.70^{\mathrm{b}, \mathrm{f}}$ \\
\hline 5 & $29-58$ & $2.68^{\mathrm{a}}$ & $3.08^{\mathrm{b}, \mathrm{e}}$ & $2.64^{\mathrm{a}}$ & $2.68^{\mathrm{b}, \mathrm{f}}$ \\
\hline 6 & $59-88$ & $2.75^{\mathrm{a}}$ & $3.04^{\mathrm{b}, \mathrm{e}}$ & $2.72^{\mathrm{a}}$ & $2.65^{\mathrm{b}, \mathrm{f}}$ \\
\hline 7 & $89-118$ & $2.78^{\mathrm{a}}$ & $3.00^{\mathrm{b}, \mathrm{e}}$ & $2.67^{\mathrm{a}}$ & $2.58^{\mathrm{b}, \mathrm{f}}$ \\
\hline 8 & $119-148$ & $2.80^{\mathrm{a}, \mathrm{g}}$ & $2.94^{\mathrm{b}, \mathrm{e}}$ & $2.59^{\mathrm{a}, \mathrm{h}}$ & $2.51^{\mathrm{b}, \mathrm{f}}$ \\
\hline 9 & $149-178$ & $2.79^{\mathrm{a}, \mathrm{g}}$ & $2.86^{\mathrm{b}, \mathrm{e}}$ & $2.47^{\mathrm{c}, \mathrm{h}}$ & $2.45^{\mathrm{d}, \mathrm{f}}$ \\
\hline 10 & $179-208$ & $2.76^{\mathrm{g}}$ & $2.76^{\mathrm{e}}$ & $2.42^{\mathrm{a}, \mathrm{h}}$ & $2.39^{\mathrm{b}, \mathrm{f}}$ \\
\hline 11 & $209-238$ & $2.71^{\mathrm{a}, \mathrm{g}}$ & $2.65^{\mathrm{b}, \mathrm{e}}$ & $2.35^{\mathrm{h}}$ & $2.35^{\mathrm{f}}$ \\
\hline 12 & $239-268$ & $2.62^{\mathrm{a}, \mathrm{g}}$ & $2.50^{\mathrm{b}, \mathrm{e}}$ & $2.30^{\mathrm{h}}$ & $2.29^{\mathrm{f}}$ \\
\hline 13 & $269-298$ & $2.46^{\mathrm{a}, \mathrm{g}}$ & $2.34^{\mathrm{b}, \mathrm{e}}$ & $2.23^{\mathrm{h}}$ & $2.22^{\mathrm{f}}$ \\
\hline 14 & $299-328$ & $2.41^{\mathrm{a}, \mathrm{g}}$ & $2.26^{\mathrm{b}}$ & $2.18^{\mathrm{h}}$ & 2.19 \\
\hline
\end{tabular}

${ }^{\mathrm{a}, \mathrm{b}}$ Parity within traffic flow system and stage of lactation differ $(P<0.05)$.

${ }^{c, d}$ Parity within traffic flow system and stage of lactation tend to differ $(P<0.10)$.

e,f Traffic flow system within parity and stage of lactation differ $(P<0.05)$.

${ }^{\mathrm{g}, \mathrm{h}}$ Traffic flow system within parity and stage of lactation tend to differ $(P<0.10)$.

${ }^{1}$ Pooled SE $=0.04$.

${ }^{2}$ Pooled SE $=0.08$. 
ing interval between primiparous and multiparous cows as this may be more important than just number of milkings per day. This parameter was not evaluated in the current study but it should be investigated in future research.

Milking frequency peaked at $2.80 \pm 0.04$ milkings $/ \mathrm{d}$ (mean $\pm \mathrm{SE}$ ) between 119 and 148 DIM for primiparous cows and at $3.18 \pm 0.04$ milkings/d between 15 and 21 DIM for multiparous cows in free-flow systems. In guided-flow systems, primiparous cows reached peak milking frequency between 59 and 88 DIM at $2.72 \pm$ 0.08 milkings/d, whereas multiparous cows reached peak milking frequency between 15 and 21 DIM at 2.73 \pm 0.08 milkings $/ \mathrm{d}$.

The comparison between free- and guided-flow system showed that primiparous cows in free-flow AMS tended to have higher milking frequency during stage 3 (15 to 21 DIM) and all stages of lactation from 119 DIM until the end of the analysis period than primiparous cows in guided-flow systems. Multiparous cows had greater $(P<0.05)$ milking frequency in free-flow systems for all stages after 7 DIM than multiparous cows in guided-flow systems, except for the 14th stage (299 to 328 DIM), which was similar.

It has been well established that cows milked more frequently produce more milk (Amos et al., 1985; Erdman and Varner, 1995). In conventional milking systems, Erdman and Varner (1995) found that $3 \times / \mathrm{d}$ milking was associated with an increase of 3.5 $\mathrm{kg} / \mathrm{d}$ in milk yield/cow and a $92 \mathrm{~g} / \mathrm{d}$ increase in fat yield/cow compared with $2 \times / d$ milking. This result was independent of the productivity level of the herd. Frequent milking in early lactation has been shown to have positive effects on milk yield, and to have lasting effects on milk yield when milking frequency is reduced later in lactation. Patton et al. (2006) compared $1 \times / d$ and $3 \times / \mathrm{d}$ milking for the first $28 \mathrm{DIM}$ and $2 \times / \mathrm{d}$ milking thereafter, and Hale et al. (2003) compared $4 \times / \mathrm{d}$ milking during the first 21 DIM and thereafter milked $2 \times / d$ to $2 \times / d$ milking over the entire lactation. Results from both of these studies showed increased frequency of milking in early lactation resulted in increased milk yield that sustained beyond the early lactation period. However, Speroni et al. (2006) found no difference in milk yield of primiparous cows milked in an AMS (2.8 milkings/d) compared with primiparous cows milked in a conventional parlor $(2 \times / d)$. Their study was conducted in an experimental farm using a guided-flow cow traffic AMS.

A key benefit for many AMS farmers is the ability to increase milking frequency above $2 \times / d$ and receiving the benefits of increased milking frequency, without increasing the amount of labor needed for the successful operation of the farm, and potentially reducing the total amount of labor required (Dijkhuizen et al., 1997). Further investigation into the frequency of milking in early lactation in AMS is needed to identify whether the lack of successful milking visits for primiparous cows in early lactation is of concern, and if so what practices may be implemented to increase milking frequency for these individuals. Only 1 of the farms in the current study (a free-flow farm) housed primiparous cows separately from multiparous cows. Research on evaluating the influence of primiparous cow grouping strategy on milking frequency is also warranted.

The differences found in traffic flow systems contradicted the findings of Munksgaard et al. (2011) where no notable differences were detected between milking frequencies, behavior, or number of cows needing to be fetched for milking between free and guided traffic flow. However, it is important to note their study was conducted where the AMS was used considerably below capacity (mean of 35 cows/AMS), whereas the average in the current study was 58.6 cows/AMS. Farms in the current study with free-flow traffic fetched $8 \%$ of their cows in comparison to $5 \%$ for guided-flow farms.

The differences between guided- and free-flow systems may be influenced by factors other than the system itself, which were not assessed in the current study. Milking permission settings were not obtained from the farms, so it is possible this could be one reason for milking frequency differences between guided- and free-flow systems. In addition, we did not have detailed fetching protocol data to investigate whether this could influence the results. Approximately $80 \%$ of the farms were fetching cows $2 \times / \mathrm{d}, 13 \% 3 \times / \mathrm{d}$, and $7 \%>3 \times / \mathrm{d}$. However, we did not have information on the interval (h) between fetching events.

\section{Analysis of Failures and Refusals}

Failures. Frequency of failures was different $(P$ $<0.05$ ) between primiparous and multiparous cows during all stages of lactation in the current study; however, we suggest that the most biologically relevant differences were seen in early lactation (Table 3 ). During the first 7 DIM, primiparous cows had on average 0.067 more failures per day than multiparous cows. After the first 7 DIM, the difference between primiparous and multiparous cow rates of failures per day declined to between 0.003 and 0.039 for the remainder lactation stages. The higher frequency of failures in early lactation for primiparous cows relative to multiparous cows may partially explain the lower milking frequency of primiparous cows observed in the current study. 
Table 3. Mean count difference of failures per day between primiparous (lactation 1) and multiparous (lactation $\geq 2$ ) cows by stage of lactation (DIM) on 30 automatic milking system dairy farms in Minnesota and Wisconsin

\begin{tabular}{llccccc}
\hline Stage & DIM & Estimate & SE & $P$-value & Lower & Upper \\
\hline 1 & $1-7$ & 0.0675 & 0.0006 & $<0.0001$ & 0.0663 & 0.0686 \\
2 & $8-14$ & 0.0395 & 0.00035 & $<0.0001$ & 0.0388 & 0.0401 \\
3 & $15-21$ & 0.0257 & 0.00023 & $<0.0001$ & 0.0252 & 0.0261 \\
4 & $22-28$ & 0.0358 & 0.00032 & $<0.0001$ & 0.0351 & 0.0364 \\
5 & $29-178$ & 0.0215 & 0.00019 & $<0.0001$ & 0.0211 & 0.0219 \\
6 & $179-328$ & 0.0029 & 0.00003 & $<0.0001$ & 0.0029 & 0.0029 \\
\hline
\end{tabular}

Failures are problematic for AMS efficiency because not only does the cow leave the AMS without successful completion of milking but she is also slower and more hesitant to leave if she did not receive concentrate (Stefanowska et al., 1999). Following a failed milking event, Stefanowska et al. (1999) reported that cows returned to the AMS sooner compared with successful milking visits (within about $2 \mathrm{~h}$ compared with about $5 \mathrm{~h}$ ), which was attributed to the cow's desire to obtain additional concentrate feed, the completion of milking, or both. Additionally, Bach and Busto (2005) found that quarters that experienced milking failure (they simulated a milking failure by skipping a milking in a conventional system) produced $26 \%$ less milk in the subsequent milking event when adjusted for the extended milking interval, with greater decreases in milk yield as DIM increased.

Rodenburg (2002) found that farms in Ontario with an average of 94 cows experienced 0 to 3 culls/yr due to cows failing to adapt to the AMS, primarily because of udder conformation issues (rear teats placed too close together or too high on the rear quarters of the udder). These cows may be detected by the farmer as problems for the AMS early in lactation and be culled from the AMS milked herd, potentially leading to lower average failure rates for cows in later lactation stages.

Although the specific cause of the milking failures was not included in the current study, the rapid reduction in difference between parities for failures during early lactation might likely be attributed to a combination of factors. These may include the primiparous cows learning how to interact with the AMS to be milked successfully, the AMS's learning of the cow's udder conformation, changes in udder conformation throughout lactation, and culling individuals from the AMS milked herd that were unfit for the system due to udder conformation or other issues. Failures may also be due to a higher rate of stepping and kicking by primiparous cows (Jacobs and Siegford, 2012). On the other hand, Jago and Kerrisk (2011) found that primiparous cows adapted more quickly to being milked in a pasture-based AMS when all animals in the pen were naïve. Voluntary milkings were achieved for $92 \%$ of primiparous cows and $81 \%$ of multiparous cows within $6 \mathrm{~d}$ after their first assisted milking. In the current study, most farms had used AMS for at least 2 yr before enrollment and many multiparous cows were probably no longer considered inexperienced with the AMS.

Lely (B. Smink, Lely North America, Madison, WI, personal communication) recommends striving for $<5$ failures/AMS per day and estimates each failure to take 8 min of AMS time. Five failures/AMS per day would equate to approximately 40 min of AMS time/d being consumed by unsuccessful milking events. Jacobs and Siegford (2012) reviewed the literature and reported that attachment failure rates in studies of AMS farms ranged from 2 to $15 \%$, with lower attachment failure rates in more recently conducted studies. This might indicate a recent improvement in AMS efficiency likely being driven by technological advancements, better management of the herd, and genetic selection for cows with suitable conformation for automatic milking.

Table 4. Mean count difference of refusals per day between primiparous (lactation 1) and multiparous (lactation $\geq 2$ ) cows by stage of lactation (DIM) on 30 automatic milking system dairy farms in Minnesota and Wisconsin

\begin{tabular}{llrrrrr}
\hline Stage & DIM & Estimate & SE & $P$-value & Lower & \multicolumn{1}{c}{ Upper } \\
\hline 1 & $1-7$ & -0.571 & 0.006 & $<0.0001$ & -0.584 & -0.559 \\
2 & $8-14$ & -0.413 & 0.008 & $<0.0001$ & -0.428 & -0.398 \\
3 & $15-21$ & -0.012 & 0.007 & 0.1077 & -0.026 & 0.002 \\
4 & $22-28$ & 0.095 & 0.007 & $<0.0001$ & 0.082 & 0.108 \\
5 & $29-178$ & 0.116 & 0.002 & $<0.0001$ & 0.112 & 0.120 \\
6 & $179-328$ & 0.135 & 0.002 & $<0.0001$ & 0.131 & 0.140 \\
\hline
\end{tabular}


Refusals. Primiparous cows had a lower number of refusals $(P<0.001)$ than multiparous cows during the first 2 wk of lactation (stages 1 and 2; Table 4) in the current study. This result indicates that primiparous cows visited the AMS less frequently relative to the milking permission settings as compared with multiparous cows during this early stage of lactation. However, during wk 3 of lactation, primiparous cows had a similar $(P=0.1077)$ number of refusals/d compared with multiparous cows, and after wk 3 of lactation, primiparous cows had more refusals than multiparous cows $(P$ $<0.001)$.

Primiparous cows were visiting the AMS milking station more often than multiparous cows for the majority of their lactation, relative to the AMS permission settings for these lactation groups, as shown by a greater number of refusals. Similarly, King et al. (2017) reported that cows of lower parity had greater frequency of refusals than those of greater parity. Previous work has also found frequency of refusals to be negatively associated with number of cows per AMS (King et al., 2017). Frequency of refusals was also lower for lame cows than for those that were not lame (King et al., 2017) and lame cows required being fetched for milking more frequently due to too long milking intervals (Bach et al., 2007). Additionally, cows of lower BCS $(\leq 3)$ had fewer refusals than those of higher BCS $(\geq 3.5$; King et al., 2017). These factors were not included in the current study.

Lely (B. Smink, Lely North America, Madison, WI, personal communication) recommends a goal of maintaining $>1$ refusal/cow per day, provided at least about $150 \mathrm{~min} / \mathrm{d}$ of AMS free time are maintained. If a dairy farm is experiencing a higher number of refusals than expected, the reason for these refusals should be evaluated, as both positive factors (such as a well-balanced ration or healthy cows), as well as negative factors (such as AMS software settings or lack of feed available at the feed bunk) may be influencing this outcome.

\section{CONCLUSIONS}

Results of this study indicated that primiparous cows had a lower frequency of successful milking visits compared with multiparous cows in early lactation. Further investigation into methods for improving performance of primiparous cows in the first few weeks of lactation that will allow these individuals to express their performance potential during their first lactation are warranted. Suggestions include better training of primiparous cows to use the AMS and improved feeding management. In addition, we suggest that AMS permission settings and different management practices that optimize daily visits to the AMS might be helpful to improve overall milk yield and AMS efficiency.

\section{ACKNOWLEDGMENTS}

We thank all the dairy producers who participated in the study. We also thank Luis Espejo (St. Augustine, FL) for help with statistical analysis. In addition, we thank Lely (Lely Industries NV, Maassluis, the Netherlands) and DeLaval (DeLaval International AB, Tumba, Sweden) for technical help with AMS software data collection and Kelly Froehlich and Michael Schmitt (both from the University of Minnesota) for help with AMS data entry. Justin Siewert was partially supported by a Department of Animal Science Fellowship (University of Minnesota, St. Paul) and the John Brandt Memorial Fund Scholarship (Land O'Lakes Inc., St. Paul). This project was partially supported by Hatch Funds from the USDA National Institute of Food and Agriculture.

\section{REFERENCES}

Amos, H. E., T. Kiser, and M. Lowenstein. 1985. Influence of milking frequency on productive and reproductive efficiencies of dairy cows. J. Dairy Sci. 68:732-739. https://doi.org/10.3168/jds.S0022 $-0302(85) 80880-8$.

Bach, A., and I. Busto. 2005. Effects on milk yield of milking interval regularity and teat cup attachment failures with robotic milking systems. J. Dairy Res. 72:101-106. https://doi.org/10.1017/ S0022029904000585.

Bach, A., M. Dinarés, M. Devant, and X. Carré. 2007. Associations between lameness and production, feeding and milking attendance of Holstein cows milked with an automatic milking system. J. Dairy Res. 74:40-46. https://doi.org/10.1017/S0022029906002184.

Dijkhuizen, A. A., R. B. M. Huirne, S. B. Harsh, and R. W. Gardner. 1997. Economics of robot application. Comput. Electron. Agric. 17:111-121. https://doi.org/10.1016/S0168-1699(96)01228-8.

Erdman, R. A., and M. Varner. 1995. Fixed yield response to increased milking frequency. J. Dairy Sci. 78:1199-1203. https://doi.org/10 .3168/jds.S0022-0302(95)76738-8.

Hale, S. A., A. V. Capuco, and R. A. Erdman. 2003. Milk yield and mammary growth effects due to increased milking frequency during early lactation. J. Dairy Sci. 86:2061-2071. https://doi.org/10 .3168/jds.S0022-0302(03)73795-3.

Jacobs, J. A., and J. M. Siegford. 2012. The impact of automatic milking systems on dairy cow management, behavior, health, and welfare. J. Dairy Sci. 95:2227-2247. https://doi.org/10.3168/jds .2011-4943.

Jago, J., and K. Kerrisk. 2011. Training methods for introducing cows to a pasture-based automatic milking system. Appl. Anim. Behav. Sci. 131:79-85. https://doi.org/10.1016/j.applanim.2011.02.002.

Ketelaar-de Lauwere, C. C., A. H. Ipema, J. H. M. Metz, J. P. T. M. Noordhuizen, and W. G. P. Schouten. 1999. The influence of accessibility of concentrate on the behavior of cows milked in an automatic milking system. Neth. J. Agric. Sci. 47:1-16.

King, M. T. M., E. A. Pajor, S. J. LeBlanc, and T. J. DeVries. 2017. Cow-level associations of lameness, behavior, and milk yield of cows milked in automated systems. J. Dairy Sci. 100:4818-4828. https://doi.org/10.3168/jds.2016-12281.

Munksgaard, L., J. Rushen, A. M. de Passillé, and C. C. Krohn. 2011. Forced versus free traffic in an automated milking system. Livest. Sci. 138:244-250. https://doi.org/10.1016/j.livsci.2010.12.023. 
Patton, J., D. A. Kenny, J. F. Mee, F. P. O'Mara, D. C. Wathes, M. Cook, and J. J. Murphy. 2006. Effect of milking frequency and diet on milk production, energy balance, and reproduction in dairy cows. J. Dairy Sci. 89:1478-1487. https://doi.org/10.3168/ jds.S0022-0302(06)72215-9.

Prescott, N. B., T. T. Mottram, and A. J. F. Webster. 1998. Relative motivations of dairy cows to be milked or fed in a Y-maze and an automatic milking system. Appl. Anim. Behav. Sci. 57:23-33. https://doi.org/10.1016/S0168-1591(97)00112-3.

Rodenburg, J. 2002. Robotic milkers: What, where . . . and how much!!?? Pages 1-18 in Proc. Ohio Dairy Management Conf. Columbus, OH. Ohio State University Extension, Columbus. Accessed Apr. 30, 2018. https://www.researchgate.net/publication/ 228503938_Robotic_milkers_What_where_and_how_much.

Rodenburg, J. 2017. Robotic milking: Technology, farm design, and effects on work flow. J. Dairy Sci. 100:7729-7738.
Speroni, M., G. Pirlo, and S. Lolli. 2006. Effect of automatic milking systems on milk yield in a hot environment. J. Dairy Sci. 89:4687-4693.

Stefanowska, J., A. H. Ipema, and M. M. W. B. Hendriks. 1999. The behavior of dairy cows in an automatic milking system where selection for milking takes place in the milking stalls. Appl. Anim. Behav. Sci. 62:99-114. https://doi.org/10.1016/S0168-1591(98)00229 $-9$.

Tremblay, M., J. P. Hess, B. M. Christenson, K. K. McIntyre, B Simink, A. J. van der Kemp, L. G. de Jong, and D. Döprer. 2016 Factors associated with increased milk production for automatic milking systems. J. Dairy Sci. 99:3824-3837. https://doi.org/10 $.3168 /$ jds.2015-10152. 